\title{
Estudo das Ações Diretas de Inconstitucionalidade do Programa Mais Médicos
}

\author{
Study of Direct Unconstitutional Action of the Programa Mais Médicos
}

\section{Sindy Maciel Silva ${ }^{1}$, Leonor Maria Pacheco Santos ${ }^{2}$}

Resumo: O Programa Mais Médicos foi implantado sob a perspectiva de garantir a efetividade jurídica e social do direito à saúde. Ele integra um conjunto estratégico de ações para melhoria do atendimento aos usuários do SUS por meio de investimentos em infraestrutura de unidades de saúde e da inserção de profissionais médicos nas regiões de grande vulnerabilidade social e sanitária. O objetivo deste estudo é analisar as duas Ações Diretas de Inconstitucionalidade proposta junto ao Supremo Tribunal Federal, seu conteúdo e posições jurídico-doutrinárias dos atores envolvidos. O método utilizado foi de revisão bibliográfica de literatura acadêmico-científica, de documentos públicos e da legislação brasileira específica. Os resultados mostram que a política pública obedece aos preceitos constitucionais e apresenta-se como instrumento indispensável de eficácia social ao direito à saúde para as regiões prioritárias atendidas. Apontam, também, a necessidade de garantir uma maior integralidade na assistência e, para isso, sugere a implantação de um plano de carreira e salário para os médicos e todos os trabalhadores do SUS. Além, da realização de reformas no ensino médico e de discussões não unicamente sobre mais médicos; mas, sim a respeito de mais saúde para todos.

Palavras-chave: Programa Mais Médicos; Ações Diretas de Inconstitucionalidade; Direito à Saúde

\begin{abstract}
Mais Médicos Program was established under the perspective of ensuring legal and social effectiveness of the right to health. It integrates a set of strategic actions to improve the service to users of SUS (Unified Health System) through investments in infrastructure of health unities and the insertion of medical professionals in the regions of great social and health vulnerability. The objective of this study is to analyze the two unconstitutional Direct Actions proposed by the Supreme Court, its content and legal doctrinal positions of the actors involved. The method used was a literature review of the academic and scientific literature, public documents and specific Brazilian legislation. The results show that public policy meets the constitutional requirements and presents itself as an indispensable instrument of social effectiveness of the right to health for priority regions. It is yet highlighted the need to ensure greater completeness and assistance, for it suggests the establishment of a career and salary plan to the doctors and all workers of the SUS. In

\footnotetext{
${ }^{1}$ Sanitarista (UnB). Assistente Técnica do Ministério da Justiça e Pesquisadora colaboradora do projeto análise da efetividade da iniciativa "Mais Médicos" na realização do direito universal à saúde e na consolidação das redes de serviços de saúde. Brasília/DF, Brasil. E-mail: sindy ms@yahoo.com.br

${ }^{2}$ Pós-doutorado em Epidemiologia Materno Infantil pela London School of Hygiene and Tropical Medicine (1992); Pósgraduação em Ciência dos Alimentos e Nutrição pela Gent Universiteit, Belgium; Doutorado (PhD) em Patologia pela

University of Tennessee Center for the Health Sciences, USA e Bacharelado em Química pela Universidade de São Paulo. É Professora Adjunta concursada no Departamento de Saúde Coletiva da Universidade de Brasília, onde atua em ensino, pesquisa, extensão; ministra aulas na graduação em Saúde Coletiva e orienta alunos de pós-graduação nos cursos de Mestrado Profissional, Mestrado Acadêmico e Doutorado em Saúde Coletiva. Brasília/DF, Brasil. E-mail: leopac@unb.br
} 
addition, reforms in medical education and discussions not only about more doctors, but about more health for all.

Keywords: Mais Médicos Program; Unconstitutional Direct Action; Right to Health

Resumen: El programa Mas Médicos fue implantado para garantizar la efectividad jurídica y social del derecho a la salud. El integra un conjunto estratégico de acciones para mejorar la atención de los usuarios de SUS a través de inversiones en infraestructura de unidades de salud y de la inserción de profesionales médicos en las regiones de gran vulnerabilidad social y sanitaria. El objetivo de este estudio es analizar las acciones directas de inconstitucionalidad propuestos por el Tribunal Supremo, en su contenido y posiciones jurídico - doctrinales de los actores involucrados. El método utilizado fue la revisión bibliográfica de literatura académico-científica, de documentos públicos y de la legislación brasilera especifica. Los resultados muestran que la política pública obedece a los preceptos constitucionales y se presenta como instrumento indispensable de eficacia social al derecho de la salud para las regiones atendidas prioritariamente. Apunta también a la necesidad de garantizar una mayor integralidad en la asistencia y para eso sugiere la implementación de un plan de carrera y salario para los médicos y todos los trabajadores de SUS, la realización de reformas en la educación médica y de discusiones no solamente sobre mas médicos sino también respecto de más salud para todos.

Palabras-Ilave: Programa Mas Médicos; Constitucionalidad; Derecho a la Salud

\section{Introdução}

A saúde é compreendida, constitucionalmente, como um direito social fundamental de todos e dever do Estado (artigos 6ำ e 196 da Constituição de 1988), garantido "mediante políticas sociais e econômicas que visem à redução do risco de doença, de outros agravos e ao acesso universal e igualitário às ações e serviços para sua promoção, proteção e recuperação" (Art. 196, CF de 1988).

Nessa perspectiva, visando garantir a efetividade jurídica e social do direito à saúde, foi instituído a partir da Medida Provisória №. 621, de 08 de julho de 2013, e convertido posteriormente na Lei nº. 12.871, de outubro de 2013 o Programa Mais Médicos (BRASIL, 2013d).

O Programa integra um conjunto estratégico de ações para a melhoria do atendimento aos usuários do Sistema Único de Saúde (SUS), por intermédio de investimentos em infraestrutura de hospitais e de unidades de saúde, além de inserir mais médicos nas regiões de grande vulnerabilidade social e sanitária, tanto em municípios pequenos ou médios quanto na periferia dos grandes centros (CAMPOS, 2013; VASCONCELOS, 2014). 
A referida política tem como finalidade formar recursos humanos na área médica para o SUS sob a diretriz de oito objetivos. São eles: (I) diminuir a carência de médicos nas regiões prioritárias para o SUS; (II) fortalecer a prestação de serviços na atenção básica em saúde no País; (III) aprimorar a formação médica no País e propiciar maior experiência no campo de prática médica durante o processo de formação; (IV) ampliar a inserção do médico em formação nas unidades de atendimento do SUS; (V) fortalecer a política de educação permanente com a integração ensino-serviço; (VI) promover a troca de conhecimentos e experiências entre profissionais da saúde brasileiros e médicos formados em instituições estrangeiras; (VII) aperfeiçoar médicos para atuação nas políticas públicas de saúde do País e na organização e funcionamento do SUS e (VIII) estimular a realização de pesquisas aplicadas ao SUS (BRASIL, 2013c).

Os principais problemas dos serviços de saúde, a serem enfrentados pela citada política pública, são: (I) a baixa proporção de número de médicos para cada mil habitantes, que de acordo com a Organização Mundial da Saúde (OMS) é de 1,8. Essa proporção é considerada baixa se comparada a outros países da América Latina com perfil socioeconômico semelhante ao Brasil como a Argentina $(3,2)$ e Uruguai $(3,7)$, e de países que também possuem sistemas universais de saúde, como Canadá $(2,0)$, Reino Unido $(2,7)$, Portugal $(3,9)$ e Cuba $(6,7)$; (II) a má distribuição de profissionais médicos pelas regiões brasileiras; (III) a insuficiência da rede de atenção básica de saúde e (III) a consequente sobrecarga do SUS com atendimentos que poderiam ser evitados com serviços de prevenção (VASCONCELOS, 2014).

Depois dessa explicação inicial sobre o Programa Mais Médicos, algumas entidades e pesquisadores analisaram o impacto de sua aplicação no âmbito do direito à saúde, com base na normativa e política vigentes, principalmente as elencadas pela Constituição da República.

De acordo com o Parecer do Ministério Público Federal, №. 3451/2014, o problema da escassez e a má distribuição de médicos advêm dos baixos índices de vagas nos cursos de graduação em Medicina e da localização do domicílio profissional e residencial. À vista disso, optou-se por ampliar o número de vagas no curso de graduação em medicina, atrair médicos estrangeiros com vistos temporários, para atuarem em caráter emergencial, preventivo e com prazo definido, delimitar regiões prioritárias de atuação e estabelecer as especialidades médicas mais demandadas (BRASIL, 2014b). 
Por outro lado, a Diretoria Nacional do Centro Brasileiro de Estudos de Saúde (Cebes) alega que a má distribuição de médicos pelo país, explicada pelas precárias condições de estrutura e trabalho, e a subordinação do setor da saúde à lógica de mercado, que viola o direito social previsto na Constituição, são os principais problemas do Sistema Único de Saúde.

Campos (2013) apoia o propósito do programa, mas questiona a forma de contrato, que recruta pessoal de "maneira canhestra, a margem da lei e sem o mínimo de segurança ao profissional" (CAMPOS, 2013). Defende que as contratações precárias são um dos principais problemas do SUS e propõe a criação de uma política de pessoal. Sobre a carreira médica, defende a criação de um interstício de cinco anos em que o profissional estaria obrigado a permanecer no posto.

A Associação Médica Brasileira (AMBR) e o Conselho Federal de Medicina (CFM) alegam que a medida do governo retira dos conselhos regionais de Medicina a competência para avaliar a qualidade profissional do médico intercambista (BRASIL, 2014a). E Di Jorge (2013), questiona a natureza jurídica dos termos firmados, em especial a forma de contratação estranha semelhante à terceirização de mão de obra final, que é vedado pela administração pública.

Atualmente, tramitam no Supremo Tribunal Federal duas Ações Diretas de Inconstitucionalidade (ADIns) sobre o Programa Mais Médicos e em ambas o Relator é o Ministro Marco Aurélio Mello. A primeira ADIn n 5.035-DF é impetrada pela Associação Médica Brasileira (AMBR) e pelo Conselho Federal de Medicina (CFM); e a segunda ADIn no 5.037-DF é impetrada pela Confederação Nacional dos Trabalhadores Liberais Universitários Regulamentados (CNTU).

Depois da especificação do Programa Mais Médicos e analisando os argumentos das entidades e pesquisadores, temos como objetivo principal reunir e analisar as duas Ações Diretas de Inconstitucionalidade proposta junto ao STF, seu conteúdo e as posições jurídico-doutrinárias dos atores envolvidos. 



\section{Metodologia}

Trata-se de uma pesquisa descritiva de abordagem qualitativa. O método utilizado foi de revisão bibliográfica de literatura e de documentos públicos visando estudar a constitucionalidade do Programa Mais Médicos, a partir das posições da Câmara dos Deputados, do Senado Federal, da Presidência da República, da Advocacia-Geral da União e da Procuradoria Geral da República.

A pesquisa limitou-se a trabalhar com a legislação brasileira, em especial a Constituição da República Federativa do Brasil de 1988, a Medida Provisória № 621/2013 a Lei no 12.871/2013, as ADIns no 5.035-DF e oㅜ 5.037-DF e os Pareceres da Procuradoria Geral da República (PGR) № 3451/2014 e n 3452/2014; além, da literatura acadêmicocientífica na área.

\section{Resultados e Discussão}

A Associação Médica Brasileira (AMBR) e o Conselho Federal de Medicina (CFM) entraram, em agosto de 2013, com um pedido de Ação Direta de Inconstitucionalidade (ADIn) no Supremo Tribunal Federal (STF) contra o art. $7^{\circ}$, I, II, e $\S \S 1^{\circ}, 2^{\circ}$ e $3^{\circ}$; art. $9^{\circ}$, I, II, III, e $\S 1^{\circ}$; art. $10, \S \S 1^{\circ}, 2^{\circ}, 3^{\circ}$ e $4^{\circ}$; e art. 11 da Medida Provisória 621.

A ADIn no 5.035-DF impugna a Medida Provisória no 621/2013 e seu artigos: I) o art. $7^{\circ}$, I, II, e $\S \S 1^{\circ}, 2^{\circ}$ e $3^{\circ}$, que trata sobre a oferta do programa para médicos brasileiros e intercambistas e a ordem de prioridade durante a seleção; II) o art. 9이 I, II, III, e $\S 1 \stackrel{0}{\text {; }}$ que dispõe sobre os integrantes do projeto e as condições para participação dos médicos intercambistas; o art. $10, \S \S 1^{\circ}, 2^{\circ}, 3^{\circ}$ e $4^{\circ}$ que trata das condições para o exercício da medicina para o médico intercambista; III) e o art. 11, que afirma que as atividades desempenhadas não criam vínculo empregatício de qualquer natureza.

A Ação baseia-se nos seguintes vícios de inconstitucionalidade: (I) ausência dos requisitos da relevância e da urgência; (II) violação ao direito à saúde; (III) violação aos direitos sociais dos trabalhadores e ao princípio do concurso público; (IV) violação ao princípio da isonomia; (V) violação à autonomia universitária; (VI) dispensa de comprovação de proficiência na língua portuguesa; e (VII) violação ao princípio da licitação pública e à proteção do mercado interno como patrimônio nacional (BRASIL, 2013a). 
Ainda em agosto de 2013, a Confederação Nacional dos Trabalhadores Liberais Universitários Regulamentados (CNTU) também entrou com uma ADIn no STF contra a Medida Provisória 621 impugnando os art. 3ํa 11, 13 e 14.

A ADIn n 5.037-DF impugna a Medida Provisória no 621/2013, além dos artigos já citados na primeira ADIn n 5.035-DF, os seguintes: I) o art. 3ำ que trata da autorização para o funcionamento de curso de graduação em medicina; II) os arts., $4^{\circ}$, 5 e $6^{\circ}$ que tratam da formação médica no Brasil a partir de $1^{\circ}$ de janeiro de 2015; o art. 8ํㅜ que trata do curso de especialização ao qual estão submetidos os médicos participantes do programa; o art. 13 que trata das modalidades de bolsas custeadas pela União direcionadas aos médicos do programa; e o art. 14 que trata da seguridade obrigatória do Regime Geral de Previdência Social no âmbito do programa (BRASIL, 2013b).

A supracitada Ação baseia-se nos seguintes vícios de inconstitucionalidade: (I) violação ao princípio da legalidade; (II) ausência dos requisitos da relevância e urgência; (III) regulamentação de matéria relativa à cidadania, vedada em sede de medida provisória; (IV) mitigação do princípio do concurso público; (V) precarização das relações de trabalho, sem reconhecimento de vínculo empregatício; (VI) imposição de serviço civil obrigatório aos estudantes do curso de graduação em Medicina; (VII) violação à liberdade profissional e exercício ilegal da Medicina, sem revalidação do diploma dos médicos estrangeiros; (VIII) dispensa de proficiência na língua portuguesa; (IX) inexigência de reciprocidade dos direitos assegurados aos estrangeiros; $(X)$ violação ao princípio da isonomia quanto à residência dos pacientes alcançados, se nos centros urbanos ou nas zonas rurais; e (XI) violação à autonomia universitária.

Em agosto de 2013, o Ministro Relator Marco Aurélio Mello solicitou a prestação de informações pelos interessados, manifestação da Advocacia-Geral da União (AGU) e parecer da Procuradoria-Geral da República (PGR).

A Câmara dos Deputados informou que a matéria foi processada pelo Congresso Nacional nos estritos trâmites constitucionais e regimentais. O Senado Federal julgou as ADIn's improcedentes, alegou que a análise dos requisitos da relevância e urgência da medida provisória compete ao Presidente da República e ao Congresso Nacional, somente se admitindo exame judicial na hipótese excepcional de abuso, o que não estaria demonstrado nesta ação. A Presidência da República e a Advocacia-Geral da União argumentaram sobre todas as alegações de inconstitucionalidade, sustentaram a presença 
dos requisitos de relevância e urgência da medida provisória e concluíram pela improcedência dos pedidos (BRASIL, 2014a; BRASIL, 2014b).

Em outubro de 2013, a Medida Provisória foi convertida na Lei ํ‥ 12.871/2013. Em janeiro de 2014, a CNTU protocolou uma petição no Supremo Tribunal Federal, na qual afirmou que as alterações da lei de conversão não foram substanciais, não afetando o objeto da ação. A AMBR e o CFM também seguiram esse procedimento. As duas ADIns estão sendo julgadas no Supremo Tribunal Federal, e ambos os processos encontram-se conclusos ao Relator Ministro Marco Aurélio Mello.

Verifica-se no quadro 1, uma apresentação sucinta do mérito e alegação encontrados nas duas ADIn's e relaciona com os Pareceres da Procuradoria Geral da República (PGR) no 3451/2014 e n³452/2014.

Quadro 1: Mérito e Alegação das ADIn's n 5.035-DF e nํ⒌037-DF relacionados com os Pareceres da Procuradoria Geral da República (PGR) nº 3451/2014 e n 3452/2014.

\begin{tabular}{|c|c|c|}
\hline Mérito & $\begin{array}{c}\text { Alegação das ADIn's } \\
\text { no 5.035-DF e no } 5.037-D F\end{array}$ & $\begin{array}{c}\text { Parecer da PGR } \\
\text { no } 3451 / 2014 \text { e } n^{\circ} 3452 / 2014\end{array}$ \\
\hline $\begin{array}{l}\text { 1. Relevância e } \\
\text { urgência da } \\
\text { Medida Provisória }\end{array}$ & $\begin{array}{l}\text { Não apresenta os requisitos constitucionais da } \\
\text { relevância e da urgência, considerando que a } \\
\text { situação da gestão da saúde pública no Brasil } \\
\text { advém da incompetência e da ineficácia dos } \\
\text { poderes e que as alterações curriculares no } \\
\text { curso de graduação em Medicina somente } \\
\text { valeriam a partir de janeiro de } 2015 \text {. }\end{array}$ & $\begin{array}{l}\text { A urgência é comprovada pelos dados } \\
\text { alarmantes da precariedade do atendimento } \\
\text { médico em milhares de municípios brasileiros. }\end{array}$ \\
\hline $\begin{array}{lr}\text { 2. Direito à saúde, } \\
\text { exercício ilegal da } \\
\text { Medicinar e } \\
\text { necessidade de } \\
\text { revalidação de } \\
\text { diploma } \\
\text { estrangeiro. } \\
\end{array}$ & $\begin{array}{l}\text { Viola o direito à saúde, por admitir o exercício } \\
\text { da medicina no país, sem a revalidação do } \\
\text { diploma e por violar o princípio da legalidade. }\end{array}$ & $\begin{array}{l}\text { É vedado o exercício da medicina fora do } \\
\text { âmbito do projeto. Neste caso, a revalidação } \\
\text { não constitui comando constitucional não } \\
\text { havendo ofensa constitucional. }\end{array}$ \\
\hline $\begin{array}{l}\text { 3. Direitos sociais } \\
\text { dos trabalhadores } \\
\text { e princípio do } \\
\text { concurso público }\end{array}$ & $\begin{array}{l}\text { Ofensa ao princípio do concurso público por } \\
\text { violação aos direitos sociais dos } \\
\text { trabalhadores, pois não reconhece vínculo } \\
\text { empregatício e não garante os direitos } \\
\text { trabalhistas. }\end{array}$ & $\begin{array}{l}\text { O inciso IX do art. } 37 \text { da Constituição admite } \\
\text { seleção simplificada para as contratações de } \\
\text { pessoal por tempo determinado, uma vez } \\
\text { demonstrada a necessidade temporária de } \\
\text { excepcional interesse público. }\end{array}$ \\
\hline $\begin{array}{lr}\text { 4. Princípio } & \text { da } \\
\text { isonomia } & \text { e } \\
\text { moradia } & \text { dos } \\
\text { pacientes } & \\
\text { alcançados } & \end{array}$ & $\begin{array}{l}\text { Viola o princípio da isonomia ao admitir a } \\
\text { atuação de médicos sem submissão aos } \\
\text { mesmos requisitos e procedimentos exigidos } \\
\text { para os médicos formados no Brasil. E a } \\
\text { diferenciação no acesso à saúde segundo a } \\
\text { localização do paciente. }\end{array}$ & $\begin{array}{l}\text { A atuação dos médicos possui foco específico } \\
\text { nas regiões prioritárias para o SUS na atenção } \\
\text { básica. E as diferenças socioeconômicas entre } \\
\text { as regiões brasileiras preexistem ao Programa e } \\
\text { são expressamente reconhecidas pela } \\
\text { Constituição. }\end{array}$ \\
\hline $\begin{array}{l}\text { 5. Autonomia } \\
\text { universitária }\end{array}$ & $\begin{array}{l}\text { Viola a autonomia universitária, pois não exige } \\
\text { a revalidação do diploma dos médicos } \\
\text { formados em instituições de ensino } \\
\text { estrangeiras. }\end{array}$ & $\begin{array}{l}\text { Nada impede que a União institua, por meio de } \\
\text { medida provisória, diretrizes curriculares } \\
\text { específicas para o curso de Medicina e delegue } \\
\text { competências gerenciais ao Ministro da } \\
\text { Educação, determinando a adequação das } \\
\text { instituições de ensino superior às novas regras. }\end{array}$ \\
\hline
\end{tabular}




\begin{tabular}{|c|c|c|}
\hline Mérito & $\begin{array}{c}\text { Alegação das ADIn's } \\
\text { no 5.035-DF e no 5.037-DF }\end{array}$ & $\begin{array}{c}\text { Parecer da PGR } \\
\text { no } 3451 / 2014 \text { e n } 3452 / 2014\end{array}$ \\
\hline $\begin{array}{lr}\text { 6. Princípio } & \text { da } \\
\text { legalidade } & \text { e } \\
\text { comprovação } & \text { de } \\
\text { proficiência } & \text { na } \\
\text { língua portuguesa }\end{array}$ & $\begin{array}{l}\text { A norma não exige nível de proficiência } \\
\text { (definido pela Resolução } 1.831 \text { do CFM). E } \\
\text { viola o princípio da legalidade por não } \\
\text { apresentar os requisitos de relevância e } \\
\text { urgência para a edição de medidas provisórias }\end{array}$ & $\begin{array}{l}\text { Não há inconstitucionalidade no caso, pois } \\
\text { uma norma de hierarquia superior (a lei) } \\
\text { regulou de forma especial um assunto tratado } \\
\text { de forma diversa em norma de hierarquia } \\
\text { inferior (Resolução do CFM). E MP tem força } \\
\text { de lei, podendo regulamentar as matérias que } \\
\text { não lhe sejam vedadas pelo } \S 1^{\circ} \text { do art. } 62 \text { da } \\
\text { Constituição, com a redação dada pela } \\
\text { Emenda Constitucional } 32 \text {, de } 11 \text { de setembro } \\
\text { de } 2001 \text {. }\end{array}$ \\
\hline $\begin{array}{l}\text { 7. Licitação pública } \\
\text { e mercado interno }\end{array}$ & $\begin{array}{l}\text { Viola o princípio da licitação, previsto no art. } \\
37 \text {, XXI, da Constituição, bem como a } \\
\text { proteção do mercado interno como patrimônio } \\
\text { nacional. }\end{array}$ & $\begin{array}{l}\text { Os termos da Lei } 8.745 / 1993 \text { não se aplicam a } \\
\text { Lei } 866 / 1993 \text { E o art. } 219 \text { da Constituição não } \\
\text { é suficiente para se concluir pela reserva de } \\
\text { mercado profissional em detrimento da } \\
\text { contratação de médicos estrangeiros para } \\
\text { exercerem atividades nas áreas da educação } \\
\text { e da saúde no país. }\end{array}$ \\
\hline 8. Cidadania & $\begin{array}{l}\text { Usurpação de competência do Poder } \\
\text { Legislativo para estatuir sobre estrangeiros e a } \\
\text { concessão de visto. }\end{array}$ & $\begin{array}{l}\text { Não se trata de legislação sobre cidadania. } \\
\text { Trata-se de nova modalidade de visto } \\
\text { temporário, criada para os médicos } \\
\text { intercambistas inscritos no programa. }\end{array}$ \\
\hline $\begin{array}{l}\text { 9. Segundo ciclo do } \\
\text { curso de graduação } \\
\text { em Medicina }\end{array}$ & $\begin{array}{l}\text { Alega que a instituição do segundo ciclo no } \\
\text { curso de graduação em Medicina (art. } 4^{\circ} \text {, II, } \\
\text { da medida provisória) configura serviço civil } \\
\text { obrigatório, violando o valor social do trabalho } \\
\text { (art. } 1^{\circ} \text {, IV, da Constituição), bem como as } \\
\text { Convenções } 29 \text { e } 122 \text { da Organização } \\
\text { Internacional do Trabalho (OIT) e a } \\
\text { Convenção Americana sobre Direitos } \\
\text { Humanos. }\end{array}$ & $\begin{array}{l}\text { A norma não foi preservada na lei de } \\
\text { conversão, de modo que o pedido perdeu o } \\
\text { objeto. }\end{array}$ \\
\hline $\begin{array}{l}\text { 10. Reciprocidade } \\
\text { de direitos }\end{array}$ & $\begin{array}{l}\text { Viola o princípio da reciprocidade de direitos, } \\
\text { previsto no art. } 12, \S 10 \text {, da Constituição, visto } \\
\text { que não exige tratamento igual aos brasileiros } \\
\text { nos países que enviarem médicos } \\
\text { intercambistas para participarem do Programa } \\
\text { Mais Médicos. }\end{array}$ & $\begin{array}{l}\text { A reciprocidade em favor de brasileiros, } \\
\text { prevista no art. 12, } \S \text { 1ㅇ, da Constituição, } \\
\text { refere-se ao ordenamento jurídico de Portugal } \\
\text { e garante direitos aos portugueses com } \\
\text { residência permanente no Brasil. Não se exige } \\
\text { reciprocidade dos direitos assegurados porque } \\
\text { se trata de uma política pública brasileira, } \\
\text { orientada para os problemas, carências e } \\
\text { realidade do Brasil e do SUS. }\end{array}$ \\
\hline
\end{tabular}

Fonte: ADIn nำ5.035-DF, ADIn n 5.037-DF, Parecer da PGR nํ 3451/2014 e Parecer da PGR n 3452/2014.

* O quadro 1 não faz distinção das duas ADIn's devido a maioria dos vícios de inconstitucionalidade estarem presentes em ambas.

Sobre a ausência da relevância e urgência da medida provisória (mérito I da ADIn 5.035 e mérito II da ADIn 5.037), os requerentes alegam que a MP nº. 621/2013 não apresenta os requisitos constitucionais da relevância e da urgência, uma vez que a situação da gestão da saúde pública no Brasil advém da incompetência e da ineficácia dos poderes públicos, há décadas; e, que as alterações curriculares no curso de graduação em Medicina somente valeriam a partir de $1^{\circ}$ de janeiro de 2015. 
Os pareceres da PGR no 3451/2014 e n³452/2014 sustentam que a realização do direito constitucional à saúde é indubitavelmente relevante, especialmente se considerada a carência de profissionais no âmbito do SUS e no foco na prevenção da saúde. A urgência é comprovada pelos dados alarmantes da precariedade do atendimento médico em milhares de municípios brasileiros.

Em relação à violação do direito à saúde (mérito II da ADIn 5.035), ao exercício ilegal da Medicina e a necessidade de revalidação de diploma estrangeiro (mérito VII da ADIn 5.037), os requerentes alegam inconstitucionalidade por admitir que estrangeiros e brasileiros formados no exterior exerçam a Medicina no país, sem a revalidação do diploma, por violar o princípio da legalidade (art. 5º II, e art. 37, caput, da Constituição), e por não apresentar os requisitos de relevância e urgência para a edição de medidas provisórias.

Os pareceres da PGR no 3451/2014 e n 3452/2014 entendem que a revalidação não constitui comando constitucional, não havendo neste caso ofensa e que a medida provisória tem força de lei, podendo regulamentar as matérias que não lhe sejam vedadas pelo $\S 1^{\circ}$ do art. 62 da Constituição, com a redação dada pela Emenda Constitucional 32 , de 11 de setembro de 2001.

O Projeto Mais Médicos não prevê a revalidação do diploma estrangeiro de forma que o portador possa exercer a sua profissão em todo o território nacional, como se dispusesse de diploma brasileiro. Esse pode exercer a medicina exclusivamente para atividades de ensino, pesquisa e extensão, para áreas prioritárias para o SUS e para área de atenção básica em saúde.

Quanto à violação dos direitos sociais dos trabalhadores (mérito III da ADIn 5.035) e do princípio do concurso público (mérito III da ADIn 5.035 e IV da ADIn 5.037), os requerentes alegam que a MP nํ. 621/2013 viola os direitos sociais dos trabalhadores, haja vista que não reconhece vínculo empregatício e não garante os direitos trabalhistas, viola o regime jurídico único dos servidores públicos, previsto na redação original do art.39 da Constituição, viola os incisos II e IX do art. 37 da Constituição, pois a admissão de médicos é feita sem concurso público e, mesmo que ocorresse em caráter temporário (inciso IX), não estaria caracterizada a situação de emergência ou calamidade pública.

Os pareceres da PGR n 3451/2014 e n³452/2014 entendem que a natureza jurídica das contratações é definida no inciso IX do art. 37 da Constituição, que admite 
seleção simplificada para as contratações de pessoal por tempo determinado, uma vez demonstrada a necessidade temporária de excepcional interesse público. E que a contratação se dá em caráter temporário, para atender as necessidades emergentes de excepcional interesse público.

Com relação à violação do princípio da isonomia e moradia dos pacientes alcançados (mérito IV da ADIn 5.035 e X da ADIn 5.037), os requerentes sustentam que a MP n․ . 621/2013 viola o princípio da isonomia ao admitir a atuação profissional de médicos que não precisam se submeter aos mesmos requisitos e procedimentos exigidos para os médicos formados no Brasil e ao criar diferença no acesso à saúde segundo a localização do paciente, pois as condições de atendimento nos centros urbanos seriam muito superiores às da zona rural, visto que contariam com médicos devidamente formados e registrados no CRM da respectiva área de atuação.

Os pareceres da PGR nํ 3451/2014 e n³452/2014 sustentam que a finalidade de atuação dos médicos do Programa MM é bastante específica, com foco especial nas regiões prioritárias para o SUS e na atenção básica. As diferenças socioeconômicas entre as regiões brasileiras preexistem ao Programa e são expressamente reconhecidas pela Constituição e mesmo que se considere válida a alegação, não há violação ao texto constitucional.

Acerca da violação à autonomia universitária (mérito $V$ da ADIn 5.035 e XI da ADIn 5.037), os requerentes alegam que os arts. 3ำ 4ำ $6^{\circ}$ e $8^{\circ}$ da MP $n^{\circ}$. 621/2013 violam a autonomia universitária e a gestão democrática do ensino público (arts. 206,VI, e 207 da Constituição).

Os pareceres da PGR nํ 3451/2014 e n 3452/2014 sustentam que a autonomia universitária para a organização curricular e programática dos cursos de graduação em Medicina já se encontrava limitada pelas diretrizes gerais estabelecidas em 2001 pela Câmara de Educação Superior. E que nada impede que a União, por meio da medida provisória e da respectiva lei de conversão, institua diretrizes curriculares específicas para o curso de Medicina, delegue competências gerenciais ao Ministro da Educação e determine a adequação das instituições de ensino superior às novas regras. Nessa perspectiva, não há violação à gestão democrática do ensino público, prevista no art. 206, VI, da Constituição. 
Sobre a violação da legalidade (mérito I da ADIn 5.037) e comprovação de proficiência na língua portuguesa (mérito VI da ADIn 5.035 e VIII da ADIn 5.037) os requerentes alegam que a não exigência de proficiência na língua portuguesa violaria 0 preceito constitucional, pois a Resolução 1.831, 24/01/2008, do CFM exige que o médico com diploma de graduação obtido em universidade estrangeira apresente o Certificado de Proficiência em Língua Portuguesa para Estrangeiros (Celpe-Bras).

Os pareceres da PGR no 3451/2014 e n 3452/2014 sustentam que o Estatuto do Estrangeiro (Lei 6.815/1980) não exige a proficiência no idioma para a naturalização, mas apenas que o naturalizando saiba "ler e escrever a língua portuguesa". O Programa MM exige que o médico participante tenha domínio da língua portuguesa, dedicando parte do primeiro módulo do curso de aperfeiçoamento ao estudo do idioma, onde a não demonstração de conhecimentos suficientes para a atuação do médico estrangeiro enseja a reprovação do candidato e a sua inadmissão no programa.

Não há inconstitucionalidade no caso, pois uma norma de hierarquia superior (a Lei) regulou de forma especial um assunto tratado de forma diversa em norma de hierarquia inferior (Resolução do CFM). Nesse caso, o conflito é resolvido por meio do princípio da hierarquia normativa.

Sobre a violação ao princípio da licitação pública e à proteção do mercado interno como patrimônio nacional (mérito VII da ADIn 5.035), os requerentes alegam que o intercâmbio de médicos estrangeiros viola o princípio da licitação, previsto no art. 37, XXI, da Constituição, bem como a proteção do mercado interno como patrimônio nacional.

O parecer da PGR oㅜ 3451/2014 afirma que por se tratar de contratação, em caráter temporário, de profissionais estrangeiros, nos termos da Lei 8.745/1993, não se aplica a Lei 8.666 (institui normas para licitações e contratos da Administração Pública) de 21 de junho de 1993. E que o art. 219 da Constituição não é suficiente para se concluir pela reserva de mercado profissional em detrimento da contratação de médicos estrangeiros para exercerem atividades nas áreas da educação e da saúde no país. Portanto, não procede a alegação de ofensa ao patrimônio nacional.

Sobre a regulamentação de matéria relativa à cidadania (mérito III da ADIn 5.037), o requerente argumenta que ao garantir ao médico intercambista o visto temporário de aperfeiçoamento por três anos (art. 12), dispôs sobre cidadania, matéria que é vedada para essa espécie legislativa (art. 62, $\S 1^{\circ}$, I, "a"). Haveria, ainda, usurpação de 
competência do Poder Legislativo para legislar sobre estrangeiros e a concessão de visto. O parecer da PGR № 3452/2014 sustenta que a MP №. 621/2013 dispõe sobre a entrada e permanência, no território nacional, do médico intercambista estrangeiro, inscrito no Projeto Mais Médicos, para o Brasil e de seus dependentes legais, mediante concessão de visto temporário válido por três anos prorrogáveis. Não se trata de legislação sobre cidadania. Trata-se de nova modalidade de visto temporário, criada para os médicos intercambistas inscritos no programa.

A competência da União para legislar sobre o tema é prevista no art. 22, XV, da Constituição e os direitos do intercambista, na qualidade de estrangeiro residente no país, continuam regidos pelo Estatuto do Estrangeiro (Lei 6.815, de 19/8/1980).

A respeito da imposição de serviço civil obrigatório aos estudantes do curso de graduação em Medicina (mérito $\mathrm{VI}$ da ADIn 5.037) o requerente alega que a instituição do segundo ciclo no curso de graduação em Medicina (art. 4º, II, da medida provisória) configura serviço civil obrigatório, violando o valor social do trabalho (art. 1ํ, IV, da Constituição), bem como as Convenções 29 e 122 da Organização Internacional do Trabalho (OIT) e a Convenção Americana sobre Direitos Humanos. O parecer da PGR no 3452/2014 afirma que a norma não foi preservada na lei de conversão, de modo que o pedido perdeu o objeto.

O art. $4^{\circ}$ da Lei $12.871 / 2013$, já transcrito no tópico referente à relevância e urgência da medida provisória, dispõe que as diretrizes curriculares nacionais dos cursos de Medicina serão definidos pelo Conselho Nacional de Educação (CNE). Os $\S \S 1^{\circ}$ e $2^{\circ}$ estabelecem o período mínimo do internato médico na graduação a ser desenvolvido na Atenção Básica e em Serviço de Urgência e Emergência do SUS, sob acompanhamento acadêmico e técnico.

Sobre a inexigência de reciprocidade dos direitos assegurados aos estrangeiros (mérito IX da ADIn 5.037), o requerente alega que a MP ํo. 621/2013 não respeita o princípio da reciprocidade de direitos, previsto no art. 12 , § 1을 da Constituição, visto que não exige tratamento igual aos brasileiros nos países que enviarem médicos intercambistas para participarem do Programa Mais Médicos. O parecer da PGR no 3452/2014 sustenta que A reciprocidade em favor de brasileiros refere-se ao ordenamento jurídico de Portugal e garante direitos aos portugueses com residência permanente no Brasil. 
Não há norma na Constituição que preveja que todos os direitos assegurados a estrangeiros devem seguir o princípio da reciprocidade em favor dos brasileiros. E não se exige reciprocidade dos direitos assegurados pelo Programa Mais Médicos porque se trata de uma política pública brasileira, orientada para os problemas, carências e realidade do Brasil e do SUS.

Nessa perspectiva, ambos os pareceres concluem, ante o exposto, o parecer é pela improcedência total do pedido e declara constitucionalidade da Lei 12.871, de 22 de outubro de 2013, oriunda da conversão da Medida Provisória 621, de 8 de julho de 2013.

\section{Conclusão}

O Programa Mais Médicos, instituído por meio da Medida Provisória no 621, de julho de 2013, e convertido, posteriormente, na Lei $n^{-0} 12.871$, de outubro de 2013, foi implantado sob a perspectiva de garantir a efetividade jurídica e social do direito à saúde. O programa integra um conjunto estratégico de ações para melhoria do atendimento aos usuários do SUS por meio de investimentos em infraestrutura de unidades de saúde e da inserção de profissionais médicos nas regiões de grande vulnerabilidade social e sanitária.

Após a análise das ADIn nํ⒌035-DF e n 5.037-DF e dos pareceres da Câmara dos Deputados, do Senado Federal, da Presidência da República, da Advocacia-Geral da União e da Procuradoria- Geral da República, entende-se que tal política pública não viola (normativamente) os preceitos constitucionais e apresenta-se como instrumento de eficácia social ao direito à saúde para as regiões prioritárias atendidas.

Por fim, a oferta de médicos deverá ser acompanhada de uma maior oferta de integralidade na assistência. Para isso, é imprescindível à implantação de um plano de carreira e salário para os médicos e todos trabalhadores do SUS (como prevê a proposta da Emenda Constitucional no 454-A de 2009, que estabelece diretrizes para a organização da carreira única de Médico de Estado), a realização de reformas no ensino médico (com intuito de formar profissionais com perfil ético e humano que sejam capazes de garantir a integralidade da assistência e de atender as demandas de saúde da população brasileira) e fomentar maiores discussões não unicamente sobre mais médicos e sim a respeito de mais saúde para todos, para consolidação do direito fundamental à saúde. 


\section{Referências bibliográficas}

BRASILa. Ministério Público Federal. Procuradoria Geral da República. Parecer № 3451/2014 - ASJCONST/SAJ/PGR. Ação Direta de Inconstitucionalidade 5.035-DF. Relator: Procurador-Geral da República Rodrigo Janot Monteiro de Barros. Brasília/DF, 28 de maio de 2014. Disponível em: http://noticias.pgr.mpf.mp.br/noticias/noticias-dosite/copy of pdfs/texto 4556767\%20-3.pdf. Acesso em: 10 set. 2014.

BRASILb. Ministério Público Federal. Procuradoria Geral da República. Parecer № 3452/2014 - ASJCONST/SAJ/PGR. Ação Direta de Inconstitucionalidade 5.037-DF. Relator: Procurador-Geral da República Rodrigo Janot Monteiro de Barros. Brasília/DF, 28 de maio de 2014.2 Disponível em: http://www.stf.jus.br/portal/processo/verProcessoAndamento.asp?incidente $=4453685$ Acesso em: 10 set. 2014.

BRASILa. Supremo Tribunal Federal. Ação Direta de Inconstitucionalidade $n^{0} 5.035$. Requerentes: Associação Médica Brasileira (AMBR) e Conselho Federal de Medicina (CFM). Interessados: Presidente da República, Presidente da Câmara dos Deputados e Presidente do Senado Federal. Relator: Ministro Marco Aurélio. Brasília/DF, 23 de agosto de 2013. Disponível em:

http://www.stf.jus.br/portal/jurisprudenciarepercussao/verAndamentoProcesso.asp?incident

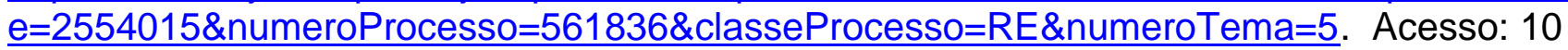
set. 2014.

BRASILb. Supremo Tribunal Federal. Ação Direta de Inconstitucionalidade no 5.037 . Requerente: Confederação Nacional dos Trabalhadores Liberais Universitários Regulamentados (CNTU). Interessados: Presidente da República e Congresso Nacional. Relator: Ministro Marco Aurélio. Brasília/DF, 23 de agosto de 2013. Disponível em: http://www.stf.jus.br/portal/processo/verProcessoAndamento. asp?incidente=4453685. Acesso em: 10 set. 2014.

BRASILc. Lei no 12.871, de 22 de outubro de 2013. Institui o Programa Mais Médicos, altera as Leis no 8.745, de 9 de dezembro de 1993, e no 6.932, de 7 de julho de 1981, e dá outras providências. Diário Oficial da República Federativa do Brasil, Brasília, 23 out. 2013. Disponível em: http://www.planalto.gov.br/ccivil 03/ ato20112014/2013/Lei/L12871.htm. Acesso em: 09 ago. 2014.

BRASILd. Medida Provisória № 621, de 8 de junho de 2013. Institui o Programa Mais Médicos e dá outras providências. Diário Oficial da República Federativa Brasil, Brasília, 09 de julho de 2013. Disponível em: http://www.planalto.gov.br/ccivil 03/ ato20112014/2013/mpv/mpv621.htm. Acesso em: 09 ago 2014.

BRASIL. Constituição da República Federativa do Brasil, de 05 outubro de 1988.

Brasília/DF. Disponível em:

http://www.planalto.gov.br/ccivil 03/constituicao/constituicaocompilado.htm. Acesso em: 10 set. 2014. 
CAMPOS. G. W. de S. A Saúde, o SUS e o Programa Mais Médicos. RADIS Comunicação e Saúde. Disponível em: http://www6.ensp.fiocruz.br/radis/radis-na-rede/saude-o-sus-e-oprograma-mais-medicos. Acesso em: 22 de ago. 2014

DI JORGE, F. M. Estudo Jurídico do Programa Mais Médico. Acta JUS - Periódico de Direito. São Paulo. v.1, n.1, p.24-34, 2013. Disponível em: http://www.mastereditora.com.br/periodico/20140216 201830.pdf. Acesso em: 22 ago. 2014.

ORGANIZAÇÃO MUNDIAL DA SAÚDE. Estadísticas Sanitarias Mundiales de 2011 e 2012. Disponível em:

http://www.who.int/gho/publications/world health statistics/ES WHS2012 Full.pdf. Acesso em: 24 set. 2014.

PAIM, J. Reforma Sanitária Brasileira: avanços, limites e perspectivas. In: Matta, G. C.; LIMA, J. C. F. Estado, sociedade e formação profissional em saúde: contradições e desafios em 20 anos de SUS. Rio de Janeiro. Disponível em: https://repositorio.ufba.br/ri/handle/ri/6234.Acesso em: 31 ago. 2014.

REZENDE, R. M. A Constitucionalidade dos Serviços Obrigatórios e o Programa Mais Médicos (Texto para Discussão no 134). Núcleo de Estudos e Pesquisas da Consultoria Legislativa. Brasília: Senado Federal. Disponível em: http://www12.senado.gov.br/publicacoes/estudos-legislativos/tipos-de-estudos/textos-paradiscussao/td-134-a-constitucionalidade-dos-servicos-obrigatorios-e-o-programa-maismedicos. Acesso em: 31 ago. 2014.

SAUDE EM DEBATE. O SUS precisa de Mais Médicos e de Muito Mais! Saúde em Debate. Rio de Janeiro, v.37, n.97, p.200-207, 2013. Disponível em: http://cebes.com.br/site/wp-content/uploads/2014/03/o-sus-precisa-de-mais-medicos-e-demuito-mais.pdf. Acesso em: 22 ago. 2014.

VASCONCELOS, D. B. Programa Mais Médicos: Exegese Constitucional da Política. Em: STRAPAZZON, C. L., RECH, A. U. e PRUX,O. I. Direitos Sociais e Políticas Públicas III. Florianópolis, CONPEDI, 2014, 517 p. 